\title{
Lactoferrin as a gene delivery vehicle to hepatocytes
}

\author{
Sangtaek Oh, ${ }^{1,2}$ Jeongkeun Rih, ${ }^{1,2}$ \\ Heungsun Kwon, ${ }^{1}$ Deog Su Hwang, ${ }^{1}$ \\ Sunyoung $\mathrm{Kim}^{1}$ and Jeongbin Yim ${ }^{1,2,3}$ \\ 1 Institute for Molecular Biology and Genetics, \\ Seoul National University, Seoul 151-742, Korea \\ 2 Department of Microbiology, Seoul National University, \\ Seoul 151-742, Korea \\ 3 Corresponding author \\ Accepted 13 May 1997
}

Abbreviations: pL, polylysine; Lf, lactoferrin; Tf, transferrin; bLf, bovine Lf; hLf, human Lf; CAT, chloramphenicol acetyltransferase; EDC, 1-ethyl-3-(3-

dimethylaminopropyl)carbodiimide specific distribution of various receptor, the delivery can be specific (Cristiano and Curiel, 1996). Second, since vector entry follows a normal physiological pathway, the delivery is not harmful to cell (Michael and Curiel, 1994). Third, this system avoid limitation of DNA size and sequence selection.

Receptor-mediated gene delivery vehicles possess two distinct functional domains. DNA binding domain is composed of polycation, such as polylysine (pL), which electrostatically interacts with DNA and forms toroid complex (Wagner et al., 1991). Ligand domain binds to a specific receptor molecule at the cell surface. Asialoglycoprotein and transferrin (Tf) are widely used to transfer foreign genes in vivo and in vitro to hepatocytes (Wu and Wu, 1987, 1988, 1992; Wagner et al., 1990; Zenke et al., 1990; Wu et al., 1991; Wilson et al., 1992; Cristiano et al., 1993; Liang et al., 1993; Stankovics et al., 1994). Recently various ligands, such as galactose, lactose, epidermal growth factor (EGF), folate, and malarial circumsporozoite protein, wsere used for gene delivery (Midoux et al., 1993; Chen et al., 1994; Gottschalk et al., 1994; Ding et al., 1995).

In this study, lactoferrin (Lf) was used as a specific ligand for gene delivery to hepatocyte. Lf belongs to the transferrin family of non-heme iron binding glycoprotein. Blood Lf originates from polymorphonuclear leucocyte which release Lf during exocytosis of specific granules. Since the liver rapidly clears Lf from circulation, the concentration of lactoferrin in the blood normally remain low, less than $20 \mathrm{nM}$ (Imber and Pizzo, 1983). Lf has at least two functions in blood. First, lactoferrin inhibits division of macrophage and granulocyte progenitor cells in bone marrow (Zucali et al., 1989). Second, Lf may regulate iron retrieval and processing (MaAbee, 1995). Hepatic cells ingest iron-lactoferrin complex and store the liberated iron with ferritin.

In previous studies (Wagner et al., 1990, Ding et al., 1995), ligand-polycation conjugates were purified by cation exchange column chromatography or gel permeation chromatography. We developed a simple method for the preparation of $\mathrm{Lf} / \mathrm{pL}$ conjugate using centrifugal filtration system. In comparison with the previous study, Lf/pL conjugate can be easily prepared and efficiently transfer foreign gene to hepatocytes.

\section{Materials and methods}

\section{Cell lines and medium}

HeLa (ATCC CCL2), Hepa 1-6 (ATCC CRL 1830) and OVCAR-3 (ATCC HTB 161) were cultured in Dulbecco's system, the receptor-mediated gene delivery system has certain advantages. First, because of the cell type-

\section{Introduction}

Receptor-mediated gene transfer has been attempted to deliver gene to cells. In comparison with viral delivery

\begin{abstract}
Using lactoferrin as the specific ligand, we developed a simplified method for preparation of molecular conjugate for gene delivery. Replacement of column filtration (Centricon, cut off size : 30,000 ), resulted
\end{abstract}

Keywords: lactoferrin, poly-L-lysine, gene delivery 
Modified Eagle's Medium (DMEM) supplemented with heat inactivated fetal bovine serum. Chang liver (ATCC CCL 13), SK-Hep1 (ATCC HTB 52) and NIH 3T3 (ATCC CRL 1688) were cultured in DMEM supplemented with $10 \%$ heat inactivated calf serum. Each medium used in this study was supplemented with $120 \mu \mathrm{g} / \mathrm{ml}$ penicillin G (Sigma, St. Louis, MO, $1690 \mathrm{U} / \mathrm{mg}$ ) and $200 \mu \mathrm{g} / \mathrm{ml}$ streptomycin sulfate (Sigma $750 \mathrm{U} / \mathrm{mg}$ ).

\section{Isolation of primary hepatocyte from mouse liver}

Mouse hepatocytes were isolated by perfusion from the liver of mouse C57BL/6 weighing 10-20 g as previously described (Berry and Friend, 1969). The mouse was anesthetized with an intraperitoneal administration of $0.3 \mathrm{ml}$ of Avertin (2,2,2-tribromoethanol, $20 \mathrm{mg} / \mathrm{ml}$, Aldrich, Milwaukee, WI). The portal vein was cannulated with a 24-gauge catheter and inferior venae cava cut. The liver was perfused with $50 \mathrm{ml}$ of perfusion medium and an additional $50 \mathrm{ml}$ of perfusion medium containing $0.5 \mathrm{mg} / \mathrm{ml}$ of collagenase (Type IV; Sigma). All the above solutions were prewarmed to $37^{\circ} \mathrm{C}$ and infused at a rate of 400 $\mathrm{ml} / \mathrm{h}$. Isolated hepatocytes were plated onto a collagen (Type I; Boerhinger Mannheim) coated culture dish at a density of $5 \times 10^{5}$ cells $/ 6-\mathrm{cm}$ dish, containing $2 \mathrm{ml}$ of DMEM supplemented with $5 \%$ fetal bovine serum, 0.1 $\mu \mathrm{M}$ dexametasone and $20 \mathrm{nM}$ insulin. After more than $80 \%$ of the cells become attached to the culture dish (after about $1 \mathrm{~h}$ ), the medium was changed. The medium was subsequently changed every $24 \mathrm{~h}$.

\section{Preparation of Lf/pL conjugate}

Bovine lactoferrin (Sigma) and human lactoferrin (Calbiochem) was conjugated to $\mathrm{pL}$ (poly-L-lysine, average molecular mass 20,000 , Sigma) by 1-ethyl-3-(3-dimethylaminopropyl)carbodiimide (EDC, Calbiochem) according to the protocol described by Halloran and Parker (1966). Reaction mixture contained $2.6 \mathrm{mg}$ of Lf and $680 \mu \mathrm{g}$ of $\mathrm{pL}$. The $\mathrm{pH}$ was adjusted to 7.0 and $2.5 \mathrm{mg}$ of EDC were added. The reaction mixture was incubated for $24 \mathrm{~h}$ at room temperature in the dark. The mixture was applied to Mono-S cation exchange column chromatography pre-equilibrated in $150 \mathrm{mM} \mathrm{NaCl}, 20 \mathrm{mM}$ HEPES, $\mathrm{pH}$ 7.4 (HBS) or to the centrifugal filtration system (Centricon, cut off size: 30,000$)$. After washing the column with HBS, bovine Lf/pL (bLf/pL) and human Lf/pL (hLf/pL) conjugate was eluted with a linear gradient of $\mathrm{NaCl}(150 \mathrm{mM}-3 \mathrm{M})$ in HBS.

\section{Preparation of Lf/pL/DNA and Tf/pL/DNA complex}

A mammalian vector system expressing the bacterial chloramphenicol acetyltransferase (CAT) and $\beta$-galactosidase were used in this study. The plasmid pCMV-CAT and PCMV-LacZ contains CAT and LacZ gene under the control of cytomegalovirus immediate early promoter. The plasmid DNA was prepared by a Qiagen column.
To prepare Lf/pL/DNA and Tf/pL/DNA complex, $80 \mu \mathrm{g}$ of $\mathrm{Lf} / \mathrm{pL}$ conjugate and $40 \mu \mathrm{g}$ of $\mathrm{Tf} / \mathrm{pL}$ conjugate in $350 \mu \mathrm{l}$ of HBS was added to $10 \mu \mathrm{g}$ of plasmid DNA in $150 \mu \mathrm{l}$ of HBS and allowed to stand for $30 \mathrm{~min}$ at room temperature. $\mathrm{Lf} / \mathrm{pL} / / \mathrm{DNA}$ and Tf/pL/DNA complex were directly added to $5 \times 10^{5}$ cells in $800 \mu \mathrm{l}$ of fresh DMEM supplemented with $2 \%$ heat inactivated fetal bovine serum and $100 \mu \mathrm{M}$ chloroquine. After $6 \mathrm{~h}$ incubation at $37^{\circ} \mathrm{C}$, the cells were transferred to the fresh medium.

\section{CAT assay and LacZ staining}

CAT assays were performed as previously described (Gorman et al., 1982). Two days after transfection, cells were harvested, washed with phosphate buffered salines (PBS), and resuspended in $0.25 \mathrm{M}$ Tris- $\mathrm{HCl}(\mathrm{pH} 7.5)$. Total proteins were prepared by 4 to 5 cycles of freeze/ thaw followed by incubation at $65^{\circ} \mathrm{C}$ for $10 \mathrm{~min}$. Equivalent amounts of protein were assayed for CAT activity. The conversion of ${ }^{14} \mathrm{C}$-chloramphenicol to its acetylated forms was determined by quantitating the intensity of each spot with phosphoimager (FUTIX BAS1000). X-gal staining was carried out as previously described (Sanes et al., 1986). The transfected cells were fixed with $0.5 \%$ glutaraldehyde in PBS and stained with 5-bromo-4-chloro3-indoyl D-galactopyranoside (X-gal, Gibco BRL).

\section{Results}

\section{Preparation of Lf/pL conjugate}

$\mathrm{hLf}$ and bLf was conjugated to $\mathrm{pL}$ (average molecular mass 20,000 ) at a 1:1 molar ratio by using EDC. Separation of the unconjugated lactoferrin from the mixture was carried out by the use of Mono $S$ cation exchange column chromatography. The $\mathrm{hLf} / \mathrm{pL}$ or bLf/pL conjugates was eluted at $1.6 \mathrm{M} \mathrm{NaCl}$. In contrast to the previous separation of $\mathrm{Tf} / \mathrm{pL}$ conjugate (Wagner et al., 1990), the unconjugated $L f$ was not detected in flow-through fractions (Figure 1). Therefore, the centrifugal filtration using Centricon was employed to isolate the $\mathrm{hLf} / \mathrm{pL}$ and $\mathrm{bLf} / \mathrm{pL}$ conjugates. The unconjugated $\mathrm{pL}$ was easily removed from Lf/pL conjugate.

\section{Optimization for the formation of conjugate- DNA complex for transfection}

In order to determine the optimal ratio between the conjugate and DNA, a gel retardation experiment was performed (Figure 2). Migration of plasmid DNA was retarded by $\mathrm{Lf} / \mathrm{pL}$ conjugate in $1 \%$ agarose gel as the concentrations of the conjugate was increased. DNA was completely retarded by Lf/pL conjugate at 2.5 mass ratio of the conjugate over DNA.

We also determined the mass ratio of conjugate over DNA for the optimal transfection efficiency. HeLa cells were transfected with $\mathrm{pCMV}$-CAT plasmid conjugated to 


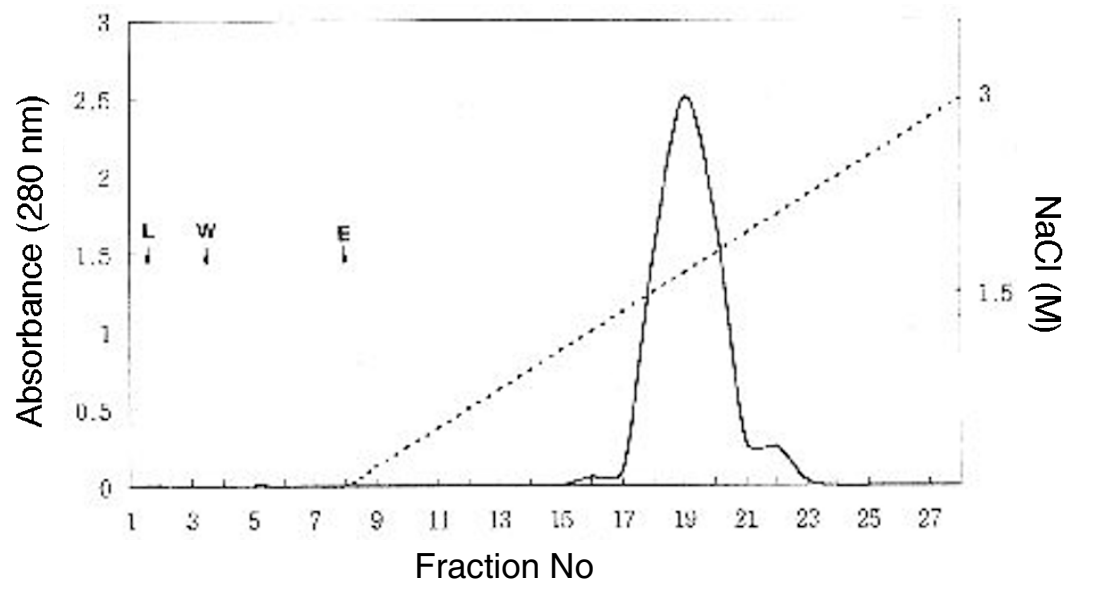

Figure 1. Purification of $L f / p L$ conjugate by Mono $S$ cation exchange column chromatography. Purification was carried out as described in the Materials and Methods. Solid line, protein concentration: dotted line, $\mathrm{NaCl}$ concentration. L, loading: W, washing: $E$, elution.

$\mathrm{hLf} / \mathrm{pL}$. For the highest transfection efficiency the ratio of $\mathrm{hLf} / \mathrm{pL}$ conjugate over DNA was 8 (Figure 3 ). This ratio was used consequently to transfect HeLa cells with pCMV-LacZ plasmid conjugate. After X-gal staining, about $10 \%$ of $\mathrm{hLf} / \mathrm{pCMV}$-LacZ transfected cells and $3 \%$ of $\mathrm{Tf} / \mathrm{pL} / \mathrm{pCMV}$-LacZ transfected cells were stained as blue, whereas pL/pCMV-LacZ transfected cells were unstained (Figure 4). These results suggest that the transfection was specifically mediated by the ligand, i.e., Lf or Tf.

\section{Gene delivery by Lf/pL conjugate to primary hepatocyte and various cell lines}

To test whether bLf/pL conjugate is able to transfer a foreign gene to primary hepatocytes isolated from C57BL/6 mouse, cells were incubated with the bLf/pL/pCMV-CAT complex. Transfer of the gene to cells was determined by CAT assay as described in the "Materials and Methods". The results presented in Figure 5 show that the bLf/pL conjugate can transfer CAT gene to the primary hepatocytes more efficiently than $\mathrm{Tf} / \mathrm{pL}$ conjugate. In order to

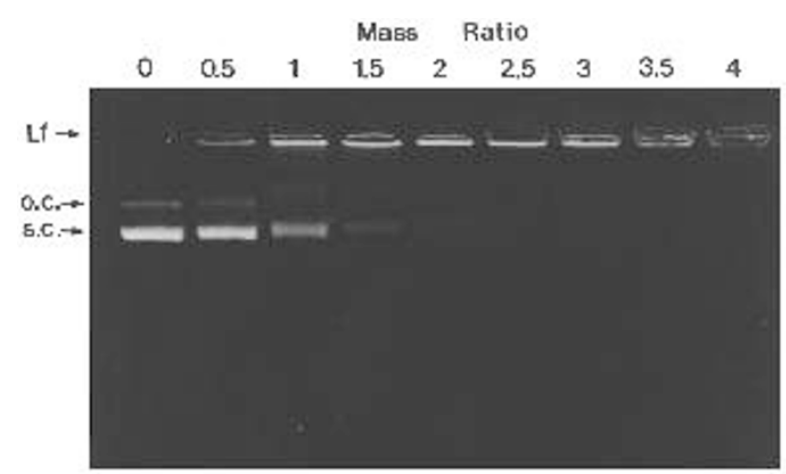

Figure 2. Retardation of Lf/pL/DNA complex. DNA/conjugate complex was formed with increasing mass ratios of $\mathrm{Lf} / \mathrm{pL}$ conjugate to $\mathrm{PCMV}$-CAT DNA. DNA was visualized with ethidium bromide. s.c., supercoiled DNA; o. c., open circle DNA; Lf, Lf/pL/DNA complex. determine hepatocyte specificity and the efficiency of Lf/pL and $\mathrm{Tf} / \mathrm{pL}$ transfection, the CAT gene was transferred to various hepatic and non hepatic cell lines, such as SKHep1 (human hepatoma cell lines), Chang liver (immortalized human hepatocyte), OVCAR-3 (human ovarian cancer cell lines), Hepa 1-6 (mouse hepatoma cell lines), and NIH 3T3 (mouse fibroblast cell lines) (Figure 6). Compared to the nonhepatocytes (NIH 3T3 and OVCAR$3)$, the transfer of pCMV-CAT to the hepatocytes was dependent upon the ligand Lf or Tf. The CAT activities detected from hepatocytes were generally higher than that from NIH 3T3 cell, although the preference of ligands was different. The ligand-independency along with the similar level of CAT activities found in OVCAR-3 human ovarian cancer cells transfected with $\mathrm{pL} / \mathrm{pCMV}-\mathrm{CAT}$, $\mathrm{hLf} / \mathrm{pL} / \mathrm{pCMV}-\mathrm{CAT}$ and Tf/pL/pCMV-CAT suggest that the transfer of $\mathrm{pCMV-CAT}$ was mediated by $\mathrm{pL}$ rather than the ligands.

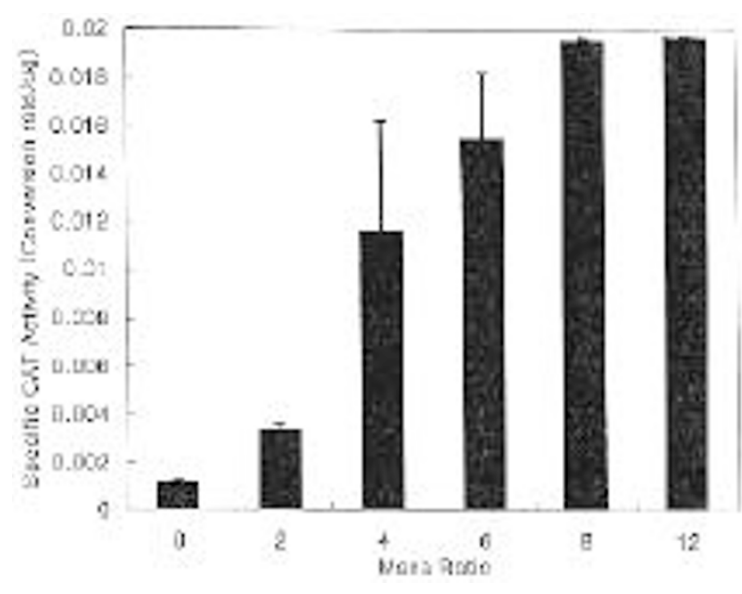

Figure 3. Determination of the optimal ratio of conjugate over DNA in vitro. HeLa cells transfected with the complex of various mass ratio of $h L f / p L$ conjugate to DNA were assayed for CAT activity $48 \mathrm{~h}$ after transfection. Two independent mesurements were made in each mass ratio. 


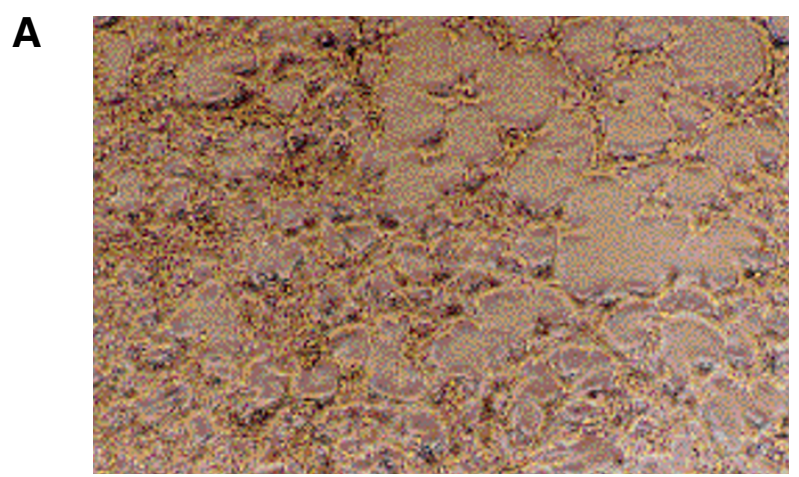

B

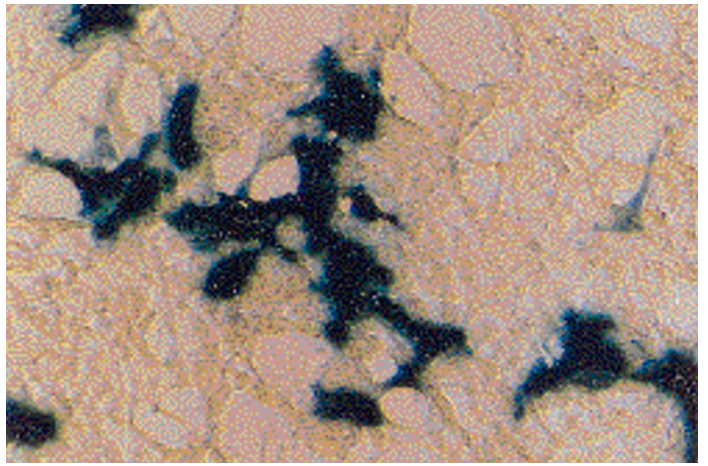

C

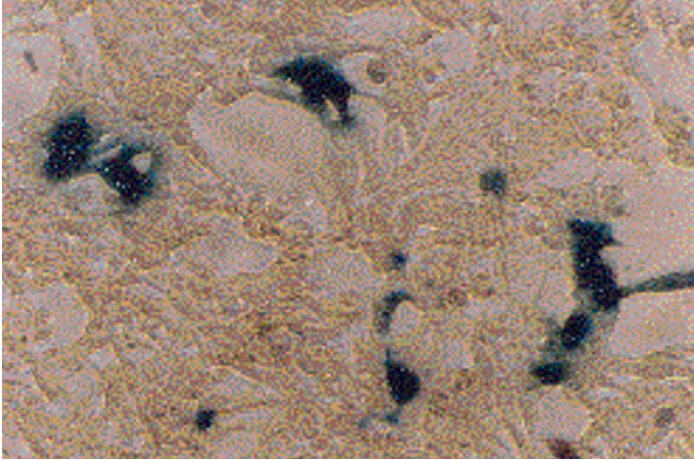

Figure 4. Visualization of transfected HeLa cells by X-gal staining. (A) pL/pCMV-LacZ; (B) Lf/pL/pCMV-LacZ complex; (C) Tf/pL/pCMV-LacZ complex.

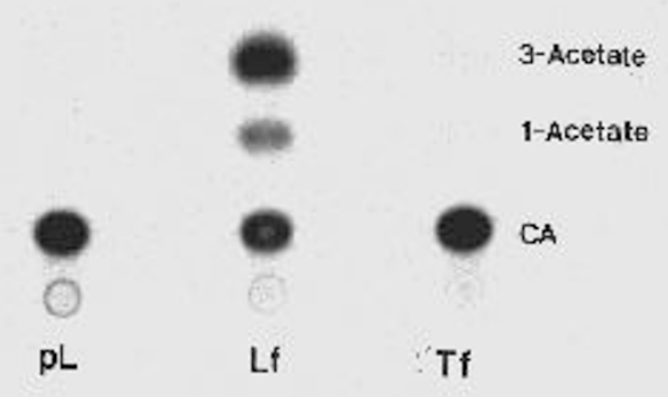

Figure 5. The expression of CAT gene in primary hepatocytes isolated from C57BI/6 mouse. pL, polylysine/pCMV-CAT complex; Lf, Lf/pL/pCMV-CAT complex; Tf, Tf/pL/pCMV-CAT complex; CA, chloramphenicol.

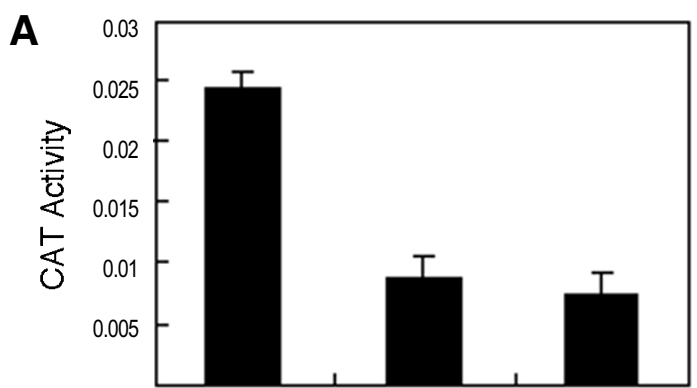

B

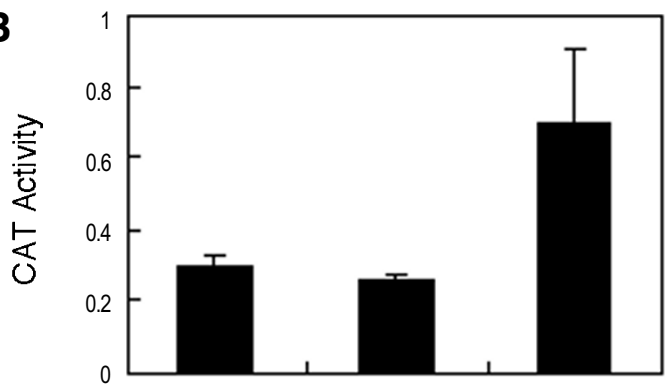

C
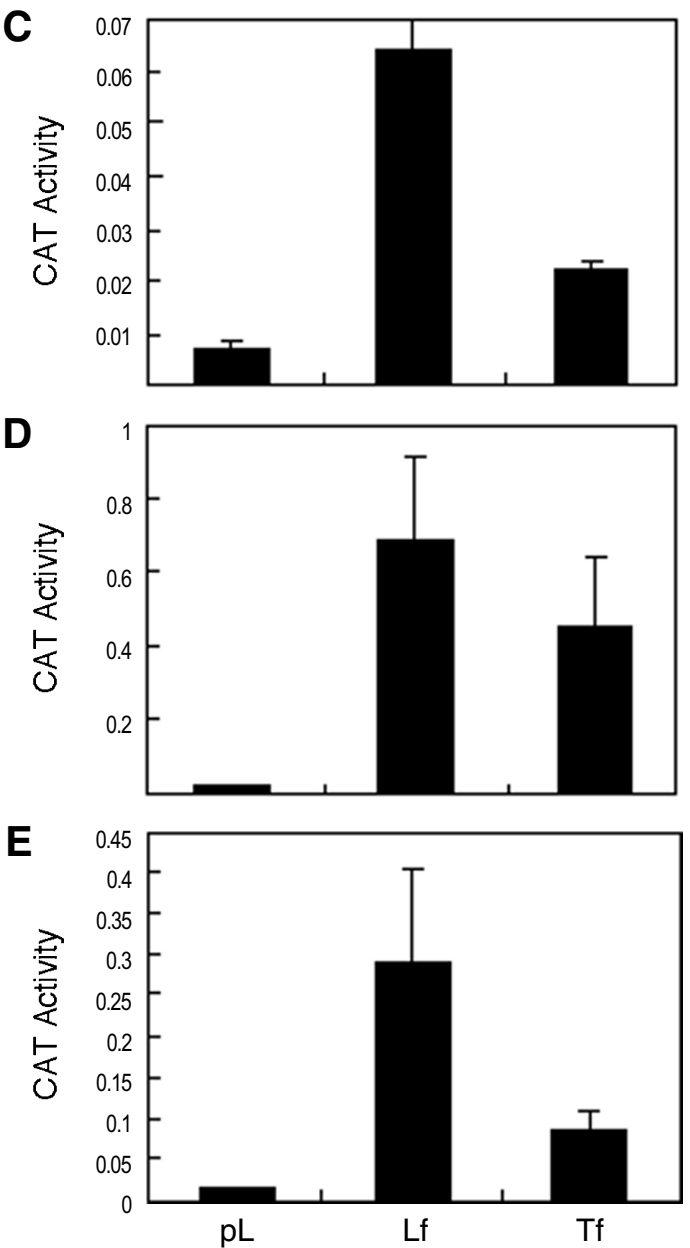

Figure 6.Expression of CAT in various cell lines. (A) mouse fibroblast NIH 3T3; (B) human ovarian cancer, OVCAR-3; (C) mouse hepatoma, Hepa 1-6; (D) human hepatoma SK-Hep1; (E) human immortalized Chang liver cell. pL, pL/pCMV-CAT complex; Lf, Lf/pL/pCMV-CAT complex; Tf, Tf/pL/pCMV-CAT complex. Three independent mesurements were made in each cell lines. 


\section{Discussion}

This study was aimed to develop new vector systems useful for transferring a foreign genes to hepatocyte. It has been reported that significant amount (15-20 mg) of Lf which is cleared from circulation daily by human liver reappears in the nucleus (He and Furmanski, 1995). Therefore, Lf was chosen as a liver specific ligand to target foreign genes to hepatocytes.

Lf was conjugated to $\mathrm{pL}$ by EDC. When the material was purified by Mono S cation exchange column chromatographic procedure developed by Wagner et al. (1990), the unconjugated Lf was not detected in the flow-through and washing fractions, rather it was eluted as a single peak at a concentration of $1.6 \mathrm{M} \mathrm{NaCl}$. Therefore, we employed a simplified centrifugal filtration method using Centricon (cut off size : 30,000) to purify the Lf/pL conjugate. Compared to the method described previously for the preparation of other conjugates, such as $\mathrm{Tf} / \mathrm{pL}$, asialogycoprotein/pL and circumsporozoit/pL (Wu et al., 1987; Wagner et al., 1990; Ding et al., 1995), our simple centrifugal filtration method using Centricon has certain advantages over the column chromatography and dialysis step. The preparation of $L f / p L$ is easier and more rapid. Since unconjugated $\mathrm{pL}$ was proved to be separated conveniently from Lf/pL conjugate, Centricon method can be applied for the preparation of other protein-pL conjugate.

The purified bLf/pL conjugate could transfer foreign genes to primary hepatocytes and the transfection efficiency was higher than that of $\mathrm{Tf} / \mathrm{pL}$ conjugate. In addition, $\mathrm{bLf} / \mathrm{pL}$ and $\mathrm{hLf} / \mathrm{pL}$ were able to transfer DNA to other cell lines including mouse Hepa 1-6 hepatoma cells and human SK-Hep1 hepatoma cell whereas the transfer to mouse NIH3T3 fibroblast cells was inefficient. The results suggest that the use of the ligand-mediated gene transfer by $\mathrm{pL}$ conjugates is limited to certain types of cancer cells and hepatocyte cell lines.

\section{Acknowledgment}

This work was supported by HAN Project Grant of the Ministry of Science and Technology, Republic of Korea.

\section{References}

Berry, M. N. and Friend, D. S. (1969) High-yield preparation of isolated liver parenchymal cells: Abochemical and fine structural study. J. Cell Biol. 43: 506-520

Chen, J., Gamou, S., Takayanlgi, A. and Shimizu, N. (1994) A novel gene delivery system using EGF receptor-mediated endocytosis. FEBS Lett. 338: 167-169

Cristiano, R. J., Smith, L. C. and Woo, S. L. C. (1993) Hepatic gene therapy: Adenovirus enhancement of receptor-mediated gene delivery and expression in primary hepatocytes. Proc. Natl. Acad. Sci. USA 90: 2122-2126

Cristiano, R. J. and Curiel, D. T. (1996) Strategies to accomplish gene delivery via the receptor-mediated endocytosis pathway. Cancer Gene Ther. 3: 49-57
Ding, Z., Cristiano, R. J., Roth, J. A., Takacs, B. and Kuo, M. T. (1995) Malarial circumsporozoit protein is a novel gene delivery vehicle to primary hepatocyte cultures and cultured cells. J. Biol. Chem. 270: 3667-3679

Gorman, C. M., Moffat, L. F. and Howard, B. H. (1982) Recombinant genomes which express chrolamphenicol acetyltransferase in mammalian cells. Mol. Cell. Biol. 2: 10441051

Gottschalk, S., Cristiano, R. J., Smith, L. C. and Woo, S. L. C. (1994) Folate receptor mediated DNA delivery into tumor cell: Potosomal disruption results enhanced gene expression. Gene Ther. 1: 185-191

Halloran, M. J. and Parker C. W. (1966) The preparation of nucleotide-protein conjugates: Carbodiimides as coupling agent. J. Immunol. 96: 373-378

He, J. and Furmanski, P. (1995) Sequence specificity and transcriptional activation in the binding of lactoferrin to DNA. Nature 373: 721-724

Imber, M. J. and Pizzo, S. V. (1983) Clearance and binding of native and defucosylated lactoferrin. Biochem. J. 212: 249-257

Liang, T. J., Makdisi, W. J., Sun, S., Hasegawa, K., Zhang, Y., Wands, J. R., Wu, C. H. and Wu, G. Y. (1993) Targeted transfection and expression of hepatitis B viral DNA in human hepatocellular cells J. Clin. Invest. 91: 1241-1246

Michael, S. I. and Curiel, D. T. (1994) Strategies to achieve targeted gene delivery via the receptor-mediated endocytosis pathway. Gene Ther. 1: 223-232

Midoux, P., Mendes, C., Legrand, A., Raimond, J., Mayer, R., Monsigny, M. and Roche A. C. (1993) Specific gene transfer mediated by lacto-sylated poly-L-lysine into hepatoma cell. Nucleic Acid Res. 21: 871-878

MaAbee, D. D. (1995) Isolated rat hepatocyte acquire iron from lactoferrin by endocytosis. Biochem. J. 311: 603-609

Stankovics, J., Crane, A. M., Andrews, E., Wu, C.H., Wu, G. Y. and Ledley, F. D. (1994) Overexpression of human methylmalonyl $\mathrm{Co} A$ mutase in mice after in vivo gene transfer with asialoglycoprotein/ polylysine/DNA complexes. Hum. Gene Ther. 5: 19051104

Sanes, J. R., Rubenstein, J. L. R. and Nicolas, J. (1986) Use of a recombinat retrovirus to study post-implantation cell lineage in mouse embryo. EMBO J. 5: 3133-3142

Wagner, E., Zenke, M., Cotten, M., Beng, H. and Brinstiel, M. L. (1990) Transferrinpolycation conjugates as carriers for DNA uptake into cells. Proc. Natl. Acad. Sci. USA 87: $3410-3414$

Wagner, E., Cotten, M., Foisner R. and Birnstiwl M. L. (1991) Tansferrin-polycationDNA complexes: The effect of polycations on the structure of the complex and DNA delivery to cells. Proc. Natl. Acad. Sci. USA 88: 4255-4259

Wilson, J. M., Grossman, M., Cabrera J. A., Wu, C. H. and Wu, G. Y. (1992) A novel mechanism for achieving transgene persistence in vivo after somatic gene transfer into hepatocytes. J. Biol. Chem. 267: 11483-11489

Wu, G. Y., and Wu, C. H. (1987) Receptor-mediated in vitro gene transformation by a soluble DNA carrier system. J. Biol. Chem. 262: 4429-4432

Wu, G. Y. and Wu, C. H. (1988) Receptor-mediated gene delivery and expression in vivo. J. Biol. Chem. 263: 14621-14624

Wu, G. Y., Wilson, J. M., Shalaby, F., Grossaman, M., Shafrize, D. A. and Wu, C. H. (1991) Receptor-mediated gene delivery in vivo. J. Biol. Chem. 266: 14338-14342

Wu, G. Y. and Wu, C. H. (1992) Specific inhibition of hepatitis B viral gene expression in vitro by oligonucletides. J. Biol. Chem. 267: 12436-12439

Zenke, M., Steinlein, P., Wagner, E., Cotten, M., Beug, H. and Birnstiel, M. L. (1990) Receptor-mediated endocytosis of transferrin-polyction conjugates: An efficient way to introduce DNA into hematopoietic cells. Proc. Natl. Acad. Sci. USA 87: 3655-3659

Zucali, J. R., Broxmeyer, H. E., Levy, D. and Morse, C. (1989) Lactoferrin decreases monocyte-induced fibroblast production of myeloid colony-stimulating activity by ssuppressing monocyte release of interleukin-1. Blood 74: 1531-1536 
